\title{
Prevalence of depression and associated factors among heart failure patients at cardiac follow-up clinics in government teaching hospital at Addis Ababa, Ethiopia; A cross sectional study
}

Kassahun Alemayehu

Addis Ababa University

Yohannes Ayalew

Addis Ababa University

Teshome Habte ( $\square$ teshome.habte@aau.edu.et )

Addis Ababa University

\section{Research Article}

Keywords: Depression, Heart Failure, prevalence, associated factor, Addis Ababa, Ethiopia

Posted Date: February 15th, 2022

DOI: https://doi.org/10.21203/rs.3.rs-1270052/v2

License: (9) This work is licensed under a Creative Commons Attribution 4.0 International License.

Read Full License 


\section{Abstract \\ Objective}

This study aimed to assess prevalence of depression and associated factors among heart failure patients at cardiac follow-up clinics.

\section{Methods}

Health care institution based cross-sectional study design was employed to assess the prevalence of depression and associated factors among 424 heart failure patients who were selected by using a systematic random sampling method from January 1 to 30, 2021 at four public hospitals, and the sample was proportionally allocated for each study hospital and then data were collected by using structured-interview questionnaires. Bivariate and Multivariate logistic regression analysis was done to examine the possible predictors and variables with the statistical association of P-value of $<0.05$ and a $95 \%$ confidence interval were considered.

\section{Result}

Data were gathered from heart failure in cardiac follow clinic with $100 \%$ response rate. The mean and standard deviation of the age of respondents was 52.68 and17.471years respectively. The prevalence of depression in this study was $59 \%$. According to NYHA class III and IV is highly associated with depression [(AOR:12.8(2.2-71.6),95\%Cl, $\mathrm{P}=0.004,(\mathrm{AOR}: 19.2(1.9-189.9), 95 \% \mathrm{Cl}, \mathrm{P}=0.011)]$ respectively, poor self-care behaviours[(AOR: 9.1(2.4-34.6), 95\% Cl, $\mathrm{P}=0.001)]$, alcohol use[(AOR:17.7(4.14-35.65),95\% $\mathrm{Cl}, \mathrm{P}=0.001)]$, poor social support[( AOR: 4.6(1.2-16.7),95\%Cl,P=0.020)], poor knowledge level [(AOR:5.1(1.3-20.6), $95 \% \mathrm{Cl}, \mathrm{P}=0.020)$, were associated with Depression and statistically significant.

\section{Conclusion}

The evidence from this study indicates that depression is highly prevalent among heart failure patients and age of respondent, alcohol intake, self-care behaviour, social support, knowledge level, and comorbidity was associated with depression and statistically significant. Therefore, all institutions of cardiac centre should work on screening of depression in heart failure patients, and consult psychiatrists and psychologists for early detection and measures.

\section{Introduction}

According to Global Burdon of disease study report, 62 million people suffered from problem related to heart failure and more than half of the patients were in sever stages. Depression is one of the most comorbid disorders in patients with cardiovascular disease and it is one of the main public health problems 
worldwide ${ }^{1,2}$. Depression is a common psychiatric disorder clearly seen by the presence of low mood or loss of interests associated with several other features that are present almost daily for at least two weeks. Moreover, depression ultimately impairs function and indicate a pathological mental change ${ }^{2}$.

A study indicates that depression has strong association with heart failure (HF). Depressed patients have less functionality with increased physiological activity of the heart, heart failure symptoms and impaired health-related quality of life. Moreover, HF patients with depression are at risk for re-hospitalization 3. Therefore, HF with depression, highly impact the overall quality of life and they had 2-fold increased risk of death or cardiac events. After five years diagnose $50 \%$ of HF patients will die ${ }^{4}$. Among heart failure patients with depressive symptoms there will be an increased risk of mortality 2-3 times higher than in patients without symptoms of depression ${ }^{5}$. Furthermore, hospitalized heart failure patients with depression are at particularly at high risk for mortality. Median survival is 1.7 years for men and 3.2 years for women, with only $25 \%$ of men and $38 \%$ of women surviving for the last 5 years. This mortality rate is 4-8 times greater than that of the general population with similar age $\mathrm{e}^{6,7} \mathrm{~A}$ study done in New York hospitalized heart failure (HF) patients with depression the rate from $13-77.5 \%$ and out- patient is from $13-42 \%$ and depression is five times more prevalent in HF patients compared to the whole population ${ }^{8,9}$. Another study conducted in west Amhara region in Ethiopia, the prevalence of depression among hear failure patients is $49 \%$, and Dessie were $50 \%{ }^{1,10}$.

A study done in Pakistan shows that depression is higher among single HF patients with low family care and support also the frequency of depression was higher among young unmarried HF patients ${ }^{11}$. The presence of social support has been associated with lower incidence of depression and faster remission of depressive symptoms, were as lack of social support, conflict relation-ship have been linked to the presence of depression. A systematic and meta-analysis conducted in Ethiopia indicates that depression is a common co-morbid illness among patients with diabetes ${ }^{12}$. And another meta-data analysis done in Greece, Patients classified in New York Heart Association (NYHA) in class "I to IV" of them class III and IV were more likely to be depressed than class I and II Patients ${ }^{13}$.

According to the study done in Nigeria, the New York Heart Association (NYHA) functional status is correlated with the prevalence of depression according to the study done in Nigeria, which increased steadily from $11 \%$ in patients with NYHA class I (mild), $20 \%$ class II, $38 \%$, class III, and $42 \%$ of them categorized in class IV (severe) heart failure ${ }^{14}$. Depression is associated with poor health care behaviors and additional risks factors, such as smoking, sedentary life, unhealthy dietary habits, lack of regular exercise, uncontrolled weight gain may lead to worsening of depression ${ }^{15}$. Another study done in Brazil indicates that selfcare behaviour was significantly associated with depression of the heart failure participants 16 .

A cross sectional study in west Amhara region in 2019 shows that poor knowledge of HF patient has strong association with depression. ${ }^{1,17}$ But factor associated with depression in heart failure are not assessed adequately in developing countries including Ethiopia. More importantly, no single study found 
in public hospital of at Addis Ababa. Therefore, this study aimed to assess the prevalence of depression and associated factors among heart failure patients at cardiac follow up-clinic at government teaching hospital in Addis Ababa, Ethiopia. This study finding may support for health care professionals to focuses their interventional strategies on the management of depression in heart failure patients, policy makers and responsible offices at various level of health care interventions to take appropriate measures and also serve as a base line information for researchers who are interested to conduct similar studies.

\section{Conceptual frame work}

Conceptual framework for this study was established after reviewing and adapted from different literatures related to similar sociodemographic characteristics of the study population and identified variables as illustrated in the figure 1 below, the socio-demographic factors (marital status, age, gender of the participants, educational level and occupation), self- care behavior such as smoking habit and alcohol use, psycho-social factor like cognitive, perception and social support and co-morbidity like heart failure patient with diabetic, hypertension and chronic kidney disease and stage of heart failure and associated factors of depression. The direction of the relationship between outcome variable (Depression) and explanatory variables are illustrated. ${ }^{3,12,18}$

\section{Methods And Materials 2.1. Study setting}

The study was conducted at selected public hospitals of Addis Ababa city administration, Ethiopia. Addis Ababa is the largest and the most populated capital city of Ethiopia. It is a metropolitan area with a population of estimated to be around $5,00,6000$ people in 2021 . The capital city holds 527 square kilometers of area in Ethiopia. The population density is estimated to be near 5,165 individuals per square kilometer available. Based on the 2020 population enumeration annual growth rate is $4.42 \%$. The city has 15 public hospitals from this four of them randomly selected to conduct this research study namely: Tikur Anbesa specialized hospital, St. Paulo's hospital, Yekatit 12 Hospital and Armed force specialized hospital.

A) Tikur Anbesa Specialized Hospital (TASH): built by empire Hailesilasie. TASH in1972 the hospital become the only site for training medical doctor. in 1998 the TASH the largest referral hospital in the country with 850 beds. TASH now the main teaching center for both clinical and preclinical training of most discipline and it has 200 doctors, 379 nurses, and also have 950 permanent and contract administrative staffs to support hospital activity.

B) St. Paulo's Hospital: established in 1969. It has 350 beds annually average of 300.000 patient flow and.it has more than 5 million catchment population. The hospital has 1200 clinical and non-clinical staffs.

C) Yekatit 12: Hospital: it is under the governance of Addis Ababa city administrative health bureau. The hospital provides service for population approximately 4 million people. It has 9 departments and 6 units 
with 265 beds, it is main referral hospital for treatment of burn. and the burn unit has 19 beds, 12 for adult and 7 for pediatrics.

D) Armed Force Specialized Hospital: formerly known as prince Tsehay Memorial Hospital. It changes the name after 1974 revolution. It has 350 beds, 150 doctors 300 nurses 100 administrative staffs 19,20

\subsection{Study design and period}

An institution-based cross-sectional study design was conducted from January 1 to 30, 2021.

\subsection{Study population}

All heart failure patients those who had follow- up at selected four government hospitals of cardiac centre in Addis Ababa during the study period.

\subsection{Sampling procedure and technique}

The total number of heart failure patient in the four study hospitals were $\mathbf{2 , 8 6 7}$. Hence, after the sample size was determined by using simple population proportion formula (n-424). The study sample was proportionally allocated to each study hospitals in line with proportional allocation formula.

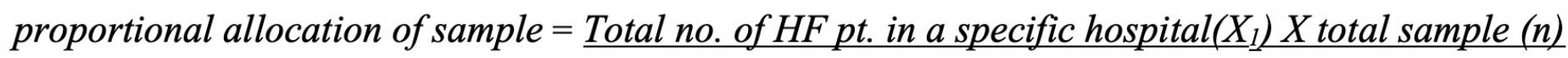
Total number of HF patients in the four study hospitals $(\mathrm{N})$

- Tikur Anbesa specialized hospital $\left(X_{1}\right)$ : the total number of heart failure patients in this hospital was $=1667$, proportional allocation of sample was calculated $n=1667 \times 424 / 2867=246$.

- St Paulo's specialized hospital $\left(X_{2}\right)$ : the total number of heart failure patients in this hospital was $=833$ proportional allocation of sample was calculated $n=, 833 \times 424 / 2867=123$.

- Armed force specialized hospital $\left(X_{3}\right)$ : the total number of heart failure patients in this hospital was $=200$ proportional allocation of sample was calculated $n=200 \times 424 / 2867=30$.

- Yekatit 12 hospital $\left(X_{4}\right)$ : the total number of heart failure patients in this hospital was=167 proportional allocation of sample was calculated $n=167 \times 424 / 2867=25$.

The study population taken from four randomly selected government hospitals. As shown in figure 2 below the sample size was proportionally allocated for each hospital. Study participants were selected from proportionally allocated study subject in each hospital using a random sampling technique from eligible patients visiting the cardiac clinic during the data collection period was interviewed.

\subsection{Procedure of Data Collection and tool used}


Data was collected by four trained BSc nurses using $5 \%$ pretested interviewer administered questionnaire and supervised by two MSc nurses. The data collection instrument includes the following components.

PHQ-9: by using a check-list that was developed on the basis of prior similar studies, the data was collected by using the Patient Health Questionnaire (PHQ-9), the questionnaire has nine items, the total score ranges from 0 to27 a score 5,10,15,20 represent cut point for mild, moderate, moderate-sever and severe depression respectively. In PHQ-9 tool there are four options $(0=$ none at all, $1=$ several days, $2=$ more than half of the days, and $3=$ nearly every day). Which have been used to screen depression symptoms from the study participants 21 . and it has $88 \%$ specificity and sensitivity. HF patients score between 1-4 categorized as having no depression. HF patient score between 5-9 was Mild depression, HF patient score between 10-14 was Moderate depression, between 15-19 categorized as having severe depression and score $>20$ was categorized as having severe depression severe depression. PHQ-9 tool Cronbach alpha value was $0.904 .21 .{ }^{21,22}$

European HF Self-care behaviours scale-9 (EHFScBC-9): The EHFScBS-9 had supportive psychometric properties of validity, reliability and precision, and it's used to measure self-care behaviours in clinical practice and research. The EHFScBS-9 has nine items of questions each item uses a 5-point Likert scale from 1 ("completely agree") to 5 ("completely disagree"). The possible score was 9 to 45 , with the level of self-care behaviour score described as the following: A score $<$ or $=2$ on each item and total score $<$ or $=$ 18 suggest high self-care behaviours, a score $>2$ on each item and total score $>18$ suggest low self-care behaviours). ${ }^{22,23}$. Alpha Cronbach was 0.806

\section{Oslo social support scale (OSSS-3)}

Evidence supports reliability and validity of the OSSS-3 as a measure of social determinants of health in the general population. The OSSS-3 consists of three items assessing the level of social support the sum score ranges from 3 to 14, with high values (>8) representing strong levels and low values (3-8) representing poor levels of social support ${ }^{14}$. Alpha Cronbach in this study was 0.869 .

The Dutch HF knowledge scale has 15 multiple choices for each item patient can choose from the three options, with one of the options being the correct answer. When a person gives the correct answer, 1 point is given whereas the answer is wrong the person receive 0 point for that question. The possible total score for knowledge of heart failure ranges from 0 to 15 and interpreted as Study subject's knowledge on HF was found to be a score of DHFKS above Median was used as a cut off for good knowledge and poor knowledge as the score is below Median ${ }^{24}$.

\subsection{Data Quality Assurance}

Structured and pre-tested questionnaire was used and also training were given for data collectors and supervisors on the objective of the study, method, contents and also how to maintain confidentiality and privacy of the study subject was strictly conducted. Data was collected by four experienced staff nurses with BSc degree and above. Pre-test was conducted on $5 \%$ of HF patients at Zewditu hospital before the 
actual data collection period and based on the finding the necessary correction made on the method and materials.

\subsection{Data Processing and Analysis}

The collected data was entered in to epi data processed and analysed by using SPSS version 25. Descriptive statistics was employed to describe the percentages and frequency distributions of the variables in the study. Adjusted odd ratio with 95\% confidence interval was estimated to measure the strength of association a P-Value of $\leq 0.05$ was used for statistical significance. The results were presented using tables and figures.

\subsection{Operational Definitions}

Depressive symptom-The individual participant had depressive symptoms when he/she has at least four positive symptoms in the PHQ-9 including Q1(Little interest or pleasure in doing things) and Q2 (Feeling down, depressed or hopeless) 25 .

Poor self-care -The individual participant had poor self-care when scored with from 9 to 45 with a higher score above $>18$ indicating poor, and lower $<18$ is good self-care of European Heart Failure Self-Care Behaviour Score-9 17 .

Poor social support-The individual participant had poor social support when she/he scored between the $3-8$ out of $14^{23}$

\section{Knowledge}

A score of DHFKS above Median was used as a cut off for good knowledge and poor knowledge as the score is < Median 26

Knowledge of HF patient defines as ability to recognize and interpreted HF symptoms ${ }^{27}$.

Low knowledge- A score of DHFKS “ $\geq 10$ ” was used as a cut off for good knowledge and poor knowledge as the score is " $<10$ ". 26

\section{Self - care behaviour}

is defined as the activity of HF patient performs to take care of their health in terms of exercise habit, abstain from cigarette smoking and alcohol intake ${ }^{17}$.

\section{Psycho-social support}

defines as help maintain a continuum of social support during or after a problem and prevent from long term mental disorder and make him to developed good perception ${ }^{23}$

Co-morbidity-The individual heart failure patient has additional chronic disease like DM, HTN, CKD 17. 


\section{Diabetes mellitus}

-a disease in which the body's ability to produce or respond to the hormone insulin is impaired, resulting in abnormal metabolism of carbohydrate and elevated level of glucose in the blood ${ }^{28}$.

\section{Hypertension}

-abnormal high blood pressure which is systolic blood pressure $>130$ and diastolic blood pressure $>85 \mathrm{mmHg} 25$.

\section{Chronic kidney disease}

is abnormality of kidney structure or function, present for $>3$ month, with implications for health ${ }^{28}$.

\section{Result}

\subsection{Socio-demographic characteristics}

A total of 424 study participants were included with $100 \%$ response rate and about 238 (55.2\%) of the study participants were female. The mean and standard deviation of age of the respondents were 52.68 and17.471years respectively. A high proportion of $134(31.6 \%)$ of the respondents were within the age group of 37-54 years and about $166(39.1 \%)$ the study reveals participants were married. The study found that one out of four participants did not attend formal education which is not able to read and write and two-third of participants were employed in government and non-governmental institutions. As shown in Table 1 below. About 36.3\% participants are having a monthly income in the range of 601-1650 Ethiopian birr. 
Table 1

Socio-demographic characteristics of heart failure patients attending cardiac followup clinic at selected government hospitals in Addis Ababa, Ethiopia. $(\mathrm{n}=424)$

\begin{tabular}{|c|c|c|c|}
\hline Socio-demographic factor & Category & Frequency & Percentage \\
\hline \multirow[t]{2}{*}{ Gender } & Male & 186 & $43.9 \%$ \\
\hline & Female & 238 & $56.1 \%$ \\
\hline \multirow[t]{4}{*}{ Age } & $18-36$ & 100 & $23.6 \%$ \\
\hline & $37-54$ & 134 & $31.6 \%$ \\
\hline & $55-72$ & 114 & $26.9 \%$ \\
\hline & $>72$ & 76 & $17.9 \%$ \\
\hline \multirow[t]{4}{*}{ Marital status } & Married & 166 & $39.1 \%$ \\
\hline & Divorced & 117 & $27.6 \%$ \\
\hline & Single & 61 & $14.4 \%$ \\
\hline & Widow & 80 & $18.9 \%$ \\
\hline \multirow[t]{5}{*}{ Educational level } & Illiterate & 110 & $25.9 \%$ \\
\hline & Elementary & 104 & $24.5 \%$ \\
\hline & Secondary & 115 & $27.1 \%$ \\
\hline & Preparatory & 40 & $9.4 \%$ \\
\hline & University level & 55 & $23.8 \%$ \\
\hline \multirow[t]{5}{*}{ Profession } & Governmental employ & 101 & $23.8 \%$ \\
\hline & Self-employ & 175 & $41.3 \%$ \\
\hline & Pension & 18 & $4.2 \%$ \\
\hline & Student & 54 & $12.7 \%$ \\
\hline & House wife & 76 & 17.9 \\
\hline \multirow[t]{6}{*}{ Monthly income per month } & $0-600$ & 9 & $2.1 \%$ \\
\hline & $601-1650$ & 154 & $36.3 \%$ \\
\hline & $1651-3200$ & 67 & $15.8 \%$ \\
\hline & $3201-5250$ & 69 & $16.3 \%$ \\
\hline & $5251-7300$ & 84 & $19.8 \%$ \\
\hline & 7301-10899 & 29 & $6.8 \%$ \\
\hline
\end{tabular}




\begin{tabular}{|llll|}
\hline Socio-demographic factor & Category & Frequency & Percentage \\
\hline & $>10899$ & 12 & $2.8 \%$ \\
\hline
\end{tabular}

\subsection{Clinical characteristics of respondents}

From the total of 424 Heart failure patients about 415 (97.9\%) of them found to have comorbidity. According to the New York heart association guideline more than one third of the participants 140(33\%) were categorized in class III, patients experienced hypertensive disorder 147(34.7\%) and diabetes mellites were 109(25.7\%) and statistically significant and chronic kidney disease accounts 19 (4.5\%).

\subsection{Self-care behaviour, social support and knowledge of respondents}

Majority of participants 257(60.6\%) were having poor knowledge and more than half $230(54.2 \%)$ of study participants had poor social support. The mean of heart failure patients with self-care behaviour score was 19.29 , with SD of 4.918 . From the total study participants, $235(55.4 \%)$ had poor self-care behaviour with cigarette smoking 120 (28.3\%). More than half $235(54.4 \%)$ of them were alcohol users.

\subsection{Prevalence of depression}

The study indicates that depression is common problem in the study area as shown figure 3 below, the prevalence of depression was 59\% (95\% Cl 54.5-63.7), being NYHA class III and IV [(AOR:12.8(2.2-71.6),95\% Cl, $\mathrm{P}=\mathbf{0 . 0 0 4}$, (AOR:19.2(1.9-189.9), 95\% Cl, $\mathrm{P}=0.011)$ ] respectively, having poor self-care behaviours[(AOR: 9.1(2.4-34.6), 95\%Cl, $\mathrm{P}=\mathbf{0 . 0 0 1}$ )], having alcohol use[(AOR: 17.7(4.14-35.65),95\% $\mathrm{Cl}, \mathrm{P}=\mathbf{0 . 0 0 1})]$, having poor social support[( $\mathrm{AOR}$ : $4.6(1.2-16.7), 95 \% \mathrm{Cl}, \mathrm{P}=0.020)]$, having poor knowledge [(AOR:5.1(1.3-20.6), 95\% Cl, $\mathrm{P}=\mathbf{0 . 0 2 0})$, and being single or unmarried [(0.108(0.03-0.47), 95\% $\mathrm{Cl}, \mathrm{P}=0.001)]$ were independently associated with Depression.

\subsection{Factor associated with depression among heart failure patients attending cardiac follow-up clinic}

The bi-variate logistic regression analysis indicates that, age of respondent, marital status, educational status, profession, NYHA classification, self-care behaviour, high alcohol intake, social support, knowledge level of the disease prognosis and co-morbidity were associated with depression among heart failure patients as shown in Table 2 below.

The multivariate logistic regression analysis also shows that, NYHA class, self-care behavior, high alcohol intake, social support, knowledge level and marital status were found to be associated with depression and statistical significance with a P-value of less than 0.05 . 
Table 2

Factor associated with Depression in bi-variate logistic regression among heart failure patients attending cardiac follow-up clinic at selected government hospitals $(\mathrm{n}=424)$

\begin{tabular}{|c|c|c|c|c|c|}
\hline \multirow[t]{2}{*}{ Variable } & \multirow[t]{2}{*}{ Category } & \multicolumn{2}{|c|}{ Depressive symptom } & \multirow[t]{2}{*}{ COR } & \multirow{2}{*}{$\begin{array}{l}\mathrm{P} \text { - } \\
\text { Value }\end{array}$} \\
\hline & & $\begin{array}{l}\text { Non } \\
\text { depression }\end{array}$ & depression & & \\
\hline \multirow[t]{2}{*}{ Marital status } & Single or un-married & $53(30.5 \%)$ & $205(82 \%)$ & $10.4(6.5-16.4)$ & $<0.001$ \\
\hline & Married & $121(69.5 \%)$ & $45(18 \%)$ & 1 & \\
\hline \multirow[t]{4}{*}{ Age } & $18-36$ & $76(43.7 \%)$ & $24(9.6 \%)$ & 1 & \\
\hline & $37-54$ & $86(49.4 \%)$ & $48(19.2 \%)$ & $1.7(0.99-3.1)$ & 0.054 \\
\hline & $55-72$ & $8(4.6 \%)$ & $106(42.4 \%)$ & $41.9((17-98.4)$ & 0.001 \\
\hline & $>72$ & $4(2.3 \%)$ & $72(28.8 \%)$ & $57(18.8-172.3)$ & $<0.001$ \\
\hline \multirow{3}{*}{$\begin{array}{l}\text { Educational } \\
\text { level }\end{array}$} & Illiterate & $13(7.5 \%)$ & $97(38.8 \%)$ & 4.8(1.-12.) & $<0.001$ \\
\hline & Higher school & $125(71.8 \%)$ & $134(53.6 \%)$ & $\begin{array}{l}0.874(0.41- \\
1.86)\end{array}$ & 0.728 \\
\hline & University level & $36(20.6 \%)$ & $19(7.6 \%)$ & 1 & \\
\hline \multirow[t]{2}{*}{ Profession } & Governmental employ & $77(44.3 \%)$ & $24(9.6 \%)$ & $7.4(4.4-12.5)$ & $<0.001$ \\
\hline & $\begin{array}{l}\text { Non-governmental } \\
\text { employ }\end{array}$ & $97(55.7 \%)$ & $226(90.4 \%)$ & 1 & \\
\hline \multirow[t]{4}{*}{ NYHA Class } & I & 75(43.1\%) & $17(6.8 \%)$ & 1 & \\
\hline & II & $69(39.7 \%)$ & $46(18.4 \%)$ & $\begin{array}{l}.019(0.007- \\
0.051)\end{array}$ & $<0.001$ \\
\hline & III & $24(13.8 \%)$ & $116(46.4 \%)$ & $.056(.023-.140)$ & $<0.001$ \\
\hline & IV & $6(3.4 \%)$ & $71(28.4 \%)$ & $\begin{array}{l}.408(.159- \\
1.048)\end{array}$ & 0.068 \\
\hline \multirow[t]{4}{*}{ Co-morbidity } & Diabetes mellites & $26(14.9 \%)$ & 83(33.2\%) & $5.9(3.4-10.3)$ & $<0.001$ \\
\hline & Hypertension & $38(21.8 \%)$ & $109(43.6 \%)$ & $5.3(3.2-8.8)$ & $<0.001$ \\
\hline & CKD & $13(7.5 \%)$ & $6(2.4 \%)$ & $0.81((0.3-2.3)$ & 0.775 \\
\hline & Non-co-morbid & $97(55.7 \%)$ & $52(20.8 \%)$ & 1 & \\
\hline \multirow[t]{2}{*}{ Alcohol intake } & Yes & $24(13.8 \%)$ & $211(84.4 \%)$ & $33.8(19.5-58.6)$ & $<0.001$ \\
\hline & No & $150(86.2 \%)$ & $39(15.6 \%)$ & 1 & \\
\hline
\end{tabular}

N.B COR=crude odd ratio, $A O R=$ adjusted odd ratio, 


\begin{tabular}{|llllll|}
\hline $\begin{array}{l}\text { Self-care } \\
\text { behaviour }\end{array}$ & Good & $163(93.7 \%)$ & $26(10.4 \%)$ & 1 & \\
\cline { 2 - 6 } & Poor & $11(6.3)$ & $224(89.6 \%)$ & $127.6(61.3-$ & $<0.001$ \\
\hline Social-support & Good & $158(90.8 \%)$ & $36(14.4 \%)$ & 1 & \\
\cline { 2 - 6 } & Poor & $16(9.2 \%)$ & $214(85.6 \%)$ & $58(31.4-109.5)$ & $<0.001$ \\
\hline Knowledge & Good & $143(82.5 \%)$ & $24(9.6 \%)$ & 1 & \\
\cline { 2 - 6 } & Poor & $31(17.8 \%)$ & $226(90.4 \%)$ & $43.3(24.5-77)$ & $<0.001$ \\
\hline N.B COR=crude odd ratio, AOR =adjusted odd ratio, & & & \\
\hline
\end{tabular}

Those heart failure patients who had NYHA Class category of III and IV were more likely to be depressed than class I and III(AOR:12.8(2.2-71.6), 95\% Cl, P= 0.004, (AOR:19.2(1.9-189.9), 95\% Cl, $P=0.011)]$ respectively. Those heart failure patients who had poor self-care behavior are 9 -fold at risk of depressive disorder as compared to those who had good self-care behavior [(AOR: 9.1(2.4-34.6),95\% Cl, $P=0.001)]$. Those heart failure patients they were alcohol users are 18 times more likely to be depressed than those who have not taken alcohol [(AOR: 17.7(4.14-35.65),95\% Cl, P=0.001)]. Those heart failure patients who were poor social support are 5 times more likely to be depressed when compared to good social support [(AOR: 4.6(1.2-16.7),95\% Cl, $\mathrm{P}=0.020)$ ] as depicted in Table 3 below. In this study those heart failure patients who had poor knowledge were more likely 5 times to be depressed as compared to good knowledge[(AOR:5.1(1.3-20.6),95\% Cl, $\mathrm{P}=0.020)]$. Those heart failure patients who are unmarried 9.25 times more likely to be depressed than married $[(0.108(0.03-0.47), 95 \% \mathrm{Cl}, \mathrm{P}=\mathbf{0 . 0 0 1})]$. 
Table 3

Factor associated with Depression in multi-variate logistic regression among heart failure patients $(n=424)$

\begin{tabular}{|c|c|c|c|c|c|}
\hline \multirow[t]{2}{*}{ Variable } & \multirow[t]{2}{*}{ Category } & \multicolumn{2}{|c|}{ Depressive symptom } & \multirow[t]{2}{*}{ AOR } & \multirow[t]{2}{*}{ P Value } \\
\hline & & $\begin{array}{l}\text { Non } \\
\text { depression }\end{array}$ & Depression & & \\
\hline \multirow[t]{2}{*}{ Marital status } & $\begin{array}{l}\text { Single or not } \\
\text { Married }\end{array}$ & $53(30.5 \%)$ & $205(82 \%)$ & $\begin{array}{l}0.108(0.03- \\
0.47)\end{array}$ & $0.001 *$ \\
\hline & Married & $121(69.5 \%)$ & $45(18 \%)$ & 1 & \\
\hline \multirow[t]{4}{*}{ NYHA Class } & 1 & $75(43.1 \%)$ & $17(6.8 \%)$ & 1 & \\
\hline & II & 69(39.7\%) & $46(18.4 \%)$ & $3.8(0.81-17.9)$ & 0.09 \\
\hline & III & $24(13.8 \%)$ & $116(46.4 \%)$ & $12.8(2.2-31.6)$ & $0.004^{*}$ \\
\hline & IV & $6(3.4 \%)$ & $71(28.4 \%)$ & 19.2(9-89.9) & 0.011 \\
\hline \multirow[t]{2}{*}{ Alcohol intake } & Yes & $24(13.8 \%)$ & $211(84.4 \%)$ & $\begin{array}{l}17.7(4.14- \\
35.65)\end{array}$ & $<0.001 *$ \\
\hline & No & $150(86.2 \%)$ & $39(15.6 \%)$ & 1 & \\
\hline \multirow{2}{*}{$\begin{array}{l}\text { Self-care } \\
\text { behaviour }\end{array}$} & Good & 163(93.7\%) & $26(10.4 \%)$ & 1 & \\
\hline & Poor & $11(6.3)$ & $224(89.6 \%)$ & $9.1(2.4-34.6)$ & $0.001 *$ \\
\hline \multirow[t]{2}{*}{ Social-support } & Good & $158(90.8 \%)$ & $36(14.4 \%)$ & 1 & \\
\hline & Poor & $16(9.2 \%)$ & $214(85.6 \%)$ & $4.6(1.2-16.7)$ & $0.020 *$ \\
\hline \multirow[t]{2}{*}{ Knowledge } & Good & $143(82.5 \%)$ & $24(9.6 \%)$ & 1 & \\
\hline & Poor & $31(17.8 \%)$ & $226(90.4 \%)$ & 5.1(1.3-20.6) & $0.020 *$ \\
\hline
\end{tabular}

\section{Discussions}

The aim of this study was to assess the prevalence and associated factor of depression among heart failure patients at cardiac follow-up clinic in selected government teaching specialized hospital of Addis Ababa. The prevalence of depression in this study reveals that $59 \%(95 \% \mathrm{Cl}, 54.5-63.7)$, this indicates that depression is highly associated with heart failure. It is obviously clear that depression is highly affecting the quality of life and efficacy of care.

A study conducted in Australia shows the prevalence of depression was $52 \%$ and South Africa in Johannesburg indicates $50 \% 8,21$. This similarity might be due to problem of depression in heart failure patient spreading across in different nations globally. The current study is higher when compared to the 
study done in Greece (20-40\%), Japanese (5.8\%), United states of America (42.1\%) 20, 27, 28. The difference might be due to difference in screening strategy, study design and sociodemographic characteristics of the study population. The prevalence of depression observed in the present study was higher than a study conducted in west Amhara region and Dessie city administration were $50 \%{ }^{1}$, this variation might be different educational background, their life style and sociodemographic characters.

This study indicated that those heart failure patients with NYHA class III and IV are more likely at risk of depressive disorders compare to those who had NYHA class I and II. The possible explanation could be individual heart failure patients with advanced stage might be worry about their worsening symptom, illness-related complication, dietary restriction and un able to do any activity and they are always dependent on others. This might be directly or indirectly lead to depression. This finding supported by a study done in Greece 2020, and study done in Ethiopia 1,15. This indicate that advanced heart failure patients need to be early evaluation of depression and cardiac clinic work in collaboration with psychiatry department to screen and therapeutic interventions. This study found that heart failure patients who had poor self-care behaviour is positively associated with depression when compared to good self-care behaviour, this might be due to poor self-care behaviour and prone to depression and potential to develop bad habit, like cigarette smoking, the use of shisha, chat chewing and lack of regular exercise. The other co-relation between psychological factors and disease outcomes, such as poor quality of life, effect of poor practice of self-care behaviour as the result heart failure patients may be potential to develop depression. This finding was in line with the study conducted in New-York, Brazil and Gondar 10,16, 17. This similarity might be due to prevention strategy of the country and pathological nature of disease process.

In this study, those heart failure patients who experienced high alcohol intake shows strongly positive association with depressive disorder than those who have not experienced alcohol use [(AOR: 17.7(4.14$35.65), 95 \% \mathrm{Cl}, \mathrm{P}=\mathbf{0 . 0 0 1})$ ] this might be due to the fact that alcohol use exposes to depression. Most alcohol users might be affected by physiological, psychological, social and economic behaviour that can alters metabolic condition of an individual life and as the result of conflict to family and society at large. This finding supported by a research done in Australia and England ${ }^{21,24}$ and this finding contradict to a research done in united kingdom showed that there is no significant association alcohol intake and depression31 The difference might be due to difference in socio-demographic characteristics of the study population. And also, this study indicates that heart failure patients who had poor social support is more likely to be depressed when compare to good social support [(AOR: $4.6(1.2-16.7), 95 \% \mathrm{Cl}, \mathrm{P}=0.020)]$. The reason might be patients who have poor social support may not share their own stressor. and also plays great role in the coping strategies, so that this situation might be directly or indirectly expose to depression. This finding supported by research done in Pakistan, USA and Greece ${ }^{25-26}$. This reveals that and contact with support group for those HF patients who had poor social support. In this study heart failure patients who had poor knowledge about their disease were having positive associated with depression [(AOR:5.1(1.3-20.6),95\% Cl, P=0.020)].This finding supported by research done in Ethiopia ${ }^{1,30}$. This indicate that health care institution should be focused on health education specially for heart failure 
patients who had poor knowledge. In general health care professionals should focus on education about their disease process and associated factors.

This study reveal that unmarried patients have positively associated with depression compared to married ones. [(AOR:0.108(0.03-0.47),95\% $\mathrm{Cl}, \mathrm{P}=0.001)]$ This might be heart failure patients who were unmarried did not share their own stressor to life partner. This finding was in line with the study conducted in Pakistan and Ethiopia 11, 27.

\section{Conclusion And Recommendations 5.1 Conclusion}

This study reveals that depressive disorder and associated factors in heart failure patients at selected government specialized teaching hospitals found to be very high and advanced stage of heart failure patients was more depressive, poor self-care behavior, alcohol users and poor social support were more potentially at risk of depressive disorder. And also, heart failure patient who had good knowledge are at lower risk of depressive disorder and having single or unmarried patients are at more risk of depressive disorder and those variables were associated with the odds of depression among heart failure patient in Addis Ababa.

\subsection{Recommendations:}

All health institution of cardiac units should work on screening of heart failure patients for depression and consult psychiatrist and Psychologist for early detection and possible measure. In addition to this health care workers should focus to teach heart failure patients about disease prognosis and associated risk factors and patient education should be a part of heart failure patient management guideline.

\section{Abbreviations}

ACS: Acute Coronary Syndrome; CHF: Congested Heart Failure; CVD: Cardio Vascular Disease; HF: Heart Failure; HADS: Hospital Anxiety Depression Scale; LMIC: Low Middle Income Country; NYHA: New York Heart Association; PHQ: Patient Health Questioner: QOL: Quality of Life; RHD: Rheumatoid Heart Disease; T2DM: Type Two Diabetics Mellitus; USA: United States America

\section{Declarations}

\section{Ethical Approval and Consent to Participate}

Ethical clearance and approval were obtained from Institutional Review Board (IRB) of Addis Ababa University, College of Health Sciences and approved by Department of Nursing and Midwifery. Permission was obtained from clinical director of each study hospitals, Matron and heads of the respective ward. After explaining the purpose of the study, possible benefit of the study and time to complete the 
questionnaire and why the participants are chosen, oral and written informed consent was obtained from each participant before proceeding the procedure. The participants were fully explained that they have the right not to participate in the study, to stop at any time in between or not to answer any questions they were not willing to answer. Confidentiality was maintained; no unauthorized person had access to the information and names or other identifiers were not recorded. All methods and subjects provided written consent, and the study was conducted in accordance with Helsinki declarations.

\section{Consent for publication: Not applicable}

\section{Availability of data and materials}

All relevant data are included with in the manuscript document. If it is necessary, it is possible to contact the corresponding author to get additional materials.

\section{Competing interests}

All authors reported no conflicts of interest for this work. The authors followed all ethical principles of scholarship in the preparation, data collection, analysis, interpretation and completion of this thesis. All scholarly matter addressed in the thesis has been given recognition through citation (cited and referenced) all sources used to prepare this document. This thesis is partial fulfilment of the requirement for graduation as Master's degree from the School of Nursing and midwifery post-graduate Studies at Addis Ababa University. Hard copy of the thesis document is found in the Library of Addis Ababa University and available to the user under the rules of the library. We have included acknowledgements and conflict of interests. We did not receive any financial support from our organization and we confirm that this work is original and has not been published elsewhere nor is it currently under consideration for publication by any journal.

\section{Funding}

The study was funded by grant office of Addis Ababa University, College of Health Sciences postgraduate office.

\section{Authors' Contributions}

The paper is the result of joint research, the contribution of every author is comparable to the others. AK. searched the literature, conception, study design, execution and acquisition of data AY and $\boldsymbol{H T}$. Data analysis, interpretation of data, Conceptualized the paper, revising it critically for important intellectual contents and Manuscript preparation and other necessary document preparation for publication. Finally, agreed to submit to the current journal; gave final approval of the version to be published; and agree to be accountable for all aspects of the work.

\section{Acknowledgements}


The authors would like to acknowledge to Addis Ababa University, College of Health Sciences, School of nursing and midwifery and study participants for their unreserved support during data collection.

\section{References}

1. Yazew K., and Beshah D. Factors Associated with Depression among Heart Failure Patients at Cardiac Follow-Up Clinics in Northwest Ethiopia, 2017: A Cross-Sectional Study. Hindawi Psychiatry J. 2019(1); 18. Doi, $10.1155 / 2019 / 6892623$

2. Dimos AK, Stougiannos PN, Kakkavas AT, Trikas AG. Depression and heart failure. Hellenic J Cardiol. 2009 Sep-Oct;50(5):410-7. PMID: 19767283.

3.York K., and Sheps D. Psychobiology of depression/distress in congestive heart failure. Heart Failure. Europe PMC, 2009, 14(1): 35-50, Doi 10.1007/s10741-008-9091-0.

4.Djarv A., and Lagergren P. "Number and burden of cardiovascular diseases in relation to health-related quality of life in a cross-sectional population-based cohort study. BMJ. 2012, 2(1),1-5: Doi 10.1136/bmj open-2012-001554

5.Abedi H., and Abdeyazdan G. Quality of Life in heart failure patients referred to the Kerman outpatient centers. J Shahrekord Univ Med Sci. 2011, 13(5), 55-63: https://doi.org/10.1186/s12955-021-01861-2

6.Polikandrioti M, Goudevenos J., Michalis L., Koutelekos J. et.al. Factors Associated with Depression and Anxiety of Hospitalized Patients with Heart Failure Europe PMC, 2015, 56(1):26-35

7. Celano CM, Villegas AC, Albanese AM, Gaggin HK, Huffman JC. Depression and Anxiety in Heart Failure: A Review. Harvard review of psychiatry. 2018, 26(4), 175-84, Doi

10.1097/HRP.0000000000000162

8.Tsabedze N, Kinsey J-L, Mpanya D, Mogashoa V, Klug E, Manga P. The Prevalence of depression in outpatients attending a chronic heart failure with reduced ejection fraction clinic in a tertiary academic center in Johannesburg, South Africa. international jornal of mental health. 2020, 1(1), 24137, Doi 10.21203/rs.3.rs-24137/v1

9.Mbakwem A., and Amadi C. Depression in Patients with Heart Failure: Is Enough Being Done Cardiac Failure. Cardiac Failure Review 2016;2(2):110-2, DOI: https:// doi.org/ 10.15420/ cfr. 2016:21:1

10.Edmealem A, Olis C. Factors Associated with Anxiety and Depression among Diabetes, Hypertension, and Heart Failure Patients at Dessie Referral Hospital, Northeast Ethiopia. Behavioral Neurology. 2020, Volume 2020, Page 3609873. Doi 10.1155/2020/3609873

11. Abdul S.., Ruqia S., Mureed H., Muhammad T., Shagufta B., \& Arslan K. Hospital Anxiety and Depression of Patients with Heart Failure in South Punjab Pakistan: A Sectional Survey Study 
Transaction Journal of Engineering, Management Applied-Sciences\&Technologies.2020, 11(6), 1-10: Doi 10.14456/iTJEMAST2020.103.

12. Henok M., Getenet D., Fasil W., Cheru T.,and Dube J. The prevalence of depression among diabetic patients in Ethiopia: a systematic review and meta-analysis. Depression Research and Treatment. Hindawi 2018., 2018(1), 1-8: Doi org/10.1155/2018/6135460.

13. T. Rutledge VAR S., Linke, B.,Greenberg, and MillsP. Depression in heart failure a meta-analytic review of prevalence, intervention effects, and associations with clinical outcomes. J Am Coll Cardiol: 2006 Oct 17;48(8):1527-37. Doi: 10.1016/j.jacc.2006.06.055

14. Iloh G, Aguocha G, Amadi A, and Chukwuonye M. Depression among ambulatory adult patients in a primary care clinic in southeastern Nigeria. Nigerian Postgraduate Medical Journal. 2018, 25(4), 204-12: Doi 10.4103/npmj.npmj_107_18

15. Polikandrioti M., Morou Z., Kotronoulas G., Evagelou H., \& Kyritsi H. Evaluation of depression in patients with congestive heart failure. Health Science Journal. 2010,4(1), 37-47,

16. Viviane M.,Luma N.,Rejane K.,André S.,Lídia A., and Rosana A. Self-care, sense of coherence and depression in patients hospitalized for decompensated heart failure, Journal of School of Nursing USP, 2015, 49(3):387-393: Doi 10.1590/s0080-623420150000300005.

17. Tsegu H., Kalayou K., Weyzer T., Haftea H., and Kbrom G. Self-Care Behavior and Associated Factors among Heart Failure Patients. Clinical Nursing Research 2020, 1(1), 1-8: Doi

$10.1177 / 1054773820961243$.

18. J.Beker TB, A.Mekonin,and E.Hailu. Predictors of adherence to self-care behavior among patients with chronic heart failure attending Jimma University Specialized Hospital Chronic Follow up Clinic, South West Ethiopia. Journal of Cardiovascular Diseases \& Diagnosis. 2014, Volume 2, Page 1-8, Doi 10.4172/2329-9517.1000180.

19. Addis Ababa, Ethiopia metroArea-population-1950-2020, 10-25

20. HailuA., Berhe H., and Aregay A. Assessment of depression prevalence and its determinants among adult patients admitted in governmental hospitals, A Cross-sectional Study Stress. 2012, Volume 4(5), Page 1882-92 Doi org/10.13040/ijPSR.0975-8232.

21. Colquhoun D.,Bunker S., Clarke D., et al. referral and treatment for depression in patients with coronary heart disease. A consensus statement from the National Heart Foundation of Australia. Volume 198, Page 483-4, Doi 10.5694/mja13.10153

22. Friedmann H., Thomas A., Chapa D., and Lee H. Poor social support is associated with increases in depression but not anxiety over 2 years in heart failure out patients, Journal of Cardio-vascular Nursing 2014 Volume 29, Page 20-8, Doi10.1097/JCN. 0b013e318276fa07. 
23. Kocalevent R.,Berg L.,Beutel M., Hinz A.,Zenger M., Härter M, et al. social support in the general population: standardization of the Oslo social support scale (OSSS-3). BMC Psychology. 2018;6(1):31. Doi 10.1186/s40359-018-0249-9.

24. van der Wal M., Jaarsma T, Moser D., and van Veldhuisen D. Development and Testing of the Dutch Heart Failure Knowledge Scale. European Journal of Cardiovascular Nursing. 2005;4(4):273-7. Doi, 10.1016/j.ejcnurse.2005.07.003

25. Simon G., Rutter C., Peterson D, Oliver M, Whiteside U, Operskalski B, et al. Does response on the PHQ9 Depression Questionnaire predict subsequent suicide attempt or suicide death Psychiatric services. 2013;64(12):1195-202.Doi,10.1176/appi. Ps201200587.

26. Sewagegn N, Fekadu, S., \& Chanie, T. Adherence to self-care behaviours and knowledge on treatment among heart in Ethiopia. Journal of Pharmaceutical Care \& Health Systems.2015, Volume 17, Page 1-7 Doi 10.4172/2376.0419S4-001

27. Suzuki T., Omori H., Tatsumi F., Nishimura K., Hagiwara N. Depression and outcomes in Japanese outpatients with cardiovascular disease. a prospective observational study. 2016, Volume 80 Page 24828, Doi org/10.1253/circj. cj-16-0829

28. Bhautesh D., Frances S.,Véronique L., et al. "Comorbid-depression and heart failure: a community cohort study. PLoS ONE. 2016, 11(6): e0158570: Doi org/10.1371/journal pone.0158570.

29. Graven L., Martorella, G., Gordon G., Grant Keltner J., and Higgins M. Predictors of Depression in Outpatients with Heart Failure. International journal of Nursing study. 2017, Volume 69, Page 57-65, Doi 10.1016/j.ijnursto.2017.01.014.

30. Khan M., Monaghan M., Klein N., Ruiz G., and John A. Associations among Depression Symptoms with Alcohol and Smoking Tobacco Use in Adult Patients with Congenital Heart Disease. Congenital heart disease. 2015, Volume 10(5), Page 243-9, Doi 10.1111/chd.12282.

31. Sin N., Kumar A., Gehi A., Whooley M., Direction of Association Between Depressive Symptoms and Lifestyle Behaviors in Patients with Coronary Heart Disease: The Heart and Soul Study. Annals of behavioral medicine: a publication of the Society of Behavioral Medicine. 2016, Volume 50(4), Page 52332. Doi 10.1007/s12160-016-9777-9.

32. Sever S., Golder S., Doherty P. Factors associated with acute depressive symptoms in patients with comorbid depression attending cardiac rehabilitation. BMC Cardiovascular Disorders. 2018, Volume 18(1), Page 230, Doi org/10.1186/s12872-018-0974-2.

33. Stafford M., and Jackson H., "Tobacco smoking predicts depression and poorer quality of life in heart disease. BMC Cardio-vascular Disorders. ,2013, Volume 13, Page 35, Doi org/10.1186/1471-2261-13-35 
34. Funk G., Chris K., and Hartl S., Classification for explaining anxious and depressive symptoms in patients with COPD-across sectional study. Respiratory Research. 2017, Volume 10, Page 1, Doi 10.1186/1465-9921-10.1

35. Ibrahim Z., Mishall A.., Jaleed A., et al. Frequency and predictors of depression in congestive heart failure. Indian Heart J. 2018, 70(3), 199-203: Doi 10.1016/j.ihj.2018.10410

\section{Figures}

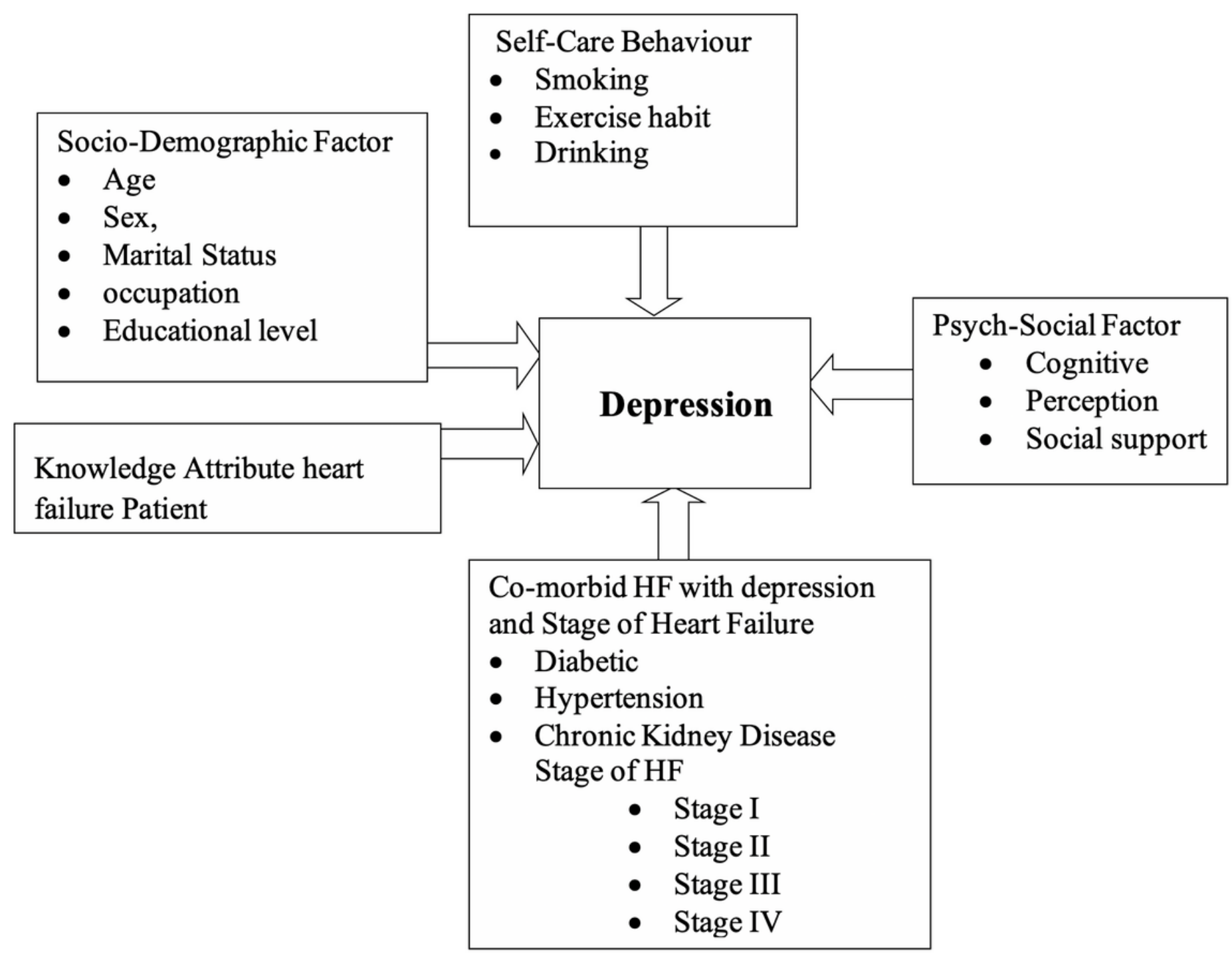

Figure 1

Conceptual framework used for the assessment of prevalence and associated factor of depression among heart failure patient at cardiac follow up clinic 


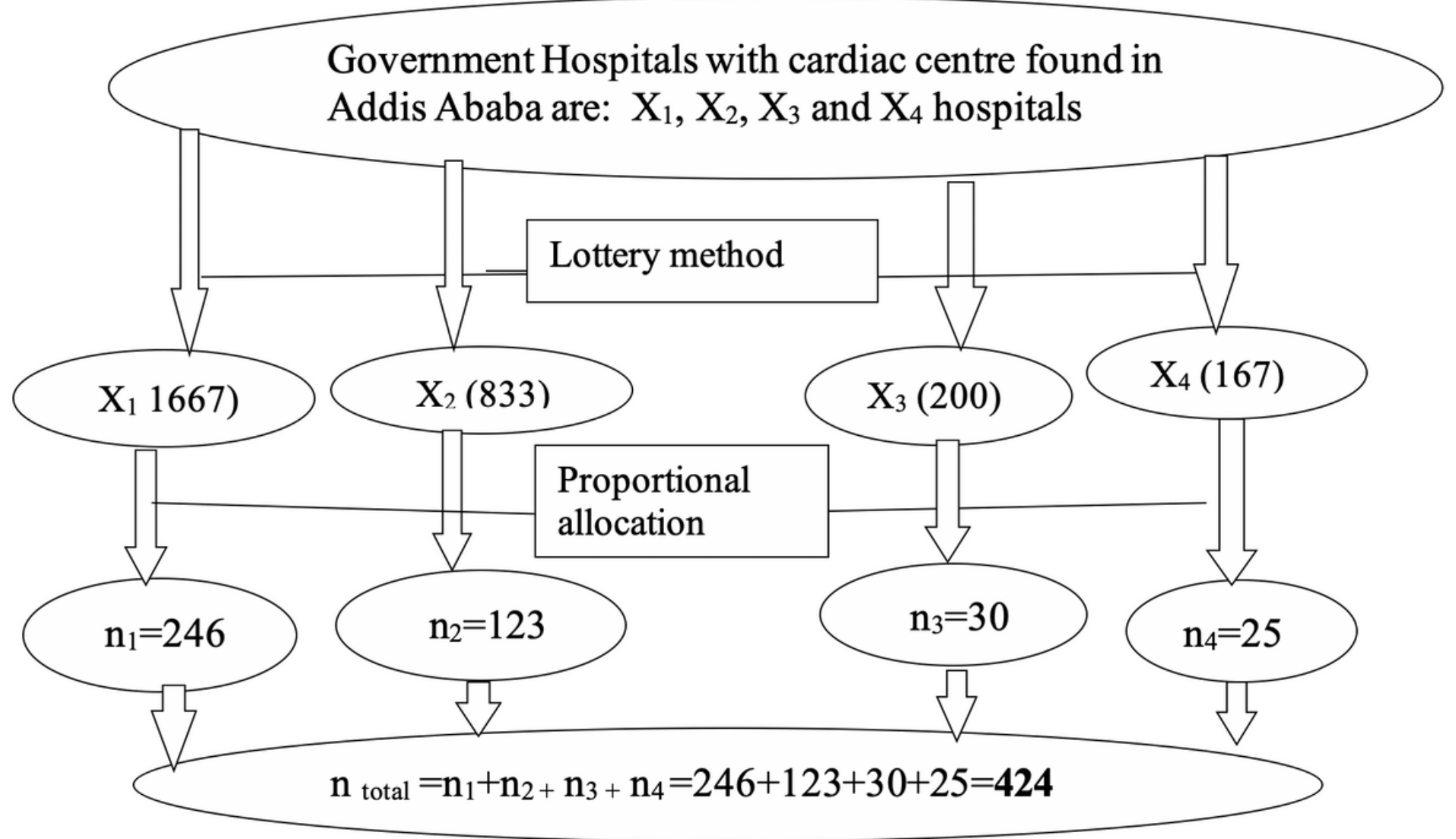

Figure 2

Schematic presentation of sampling technique and sample size proportional allocation.

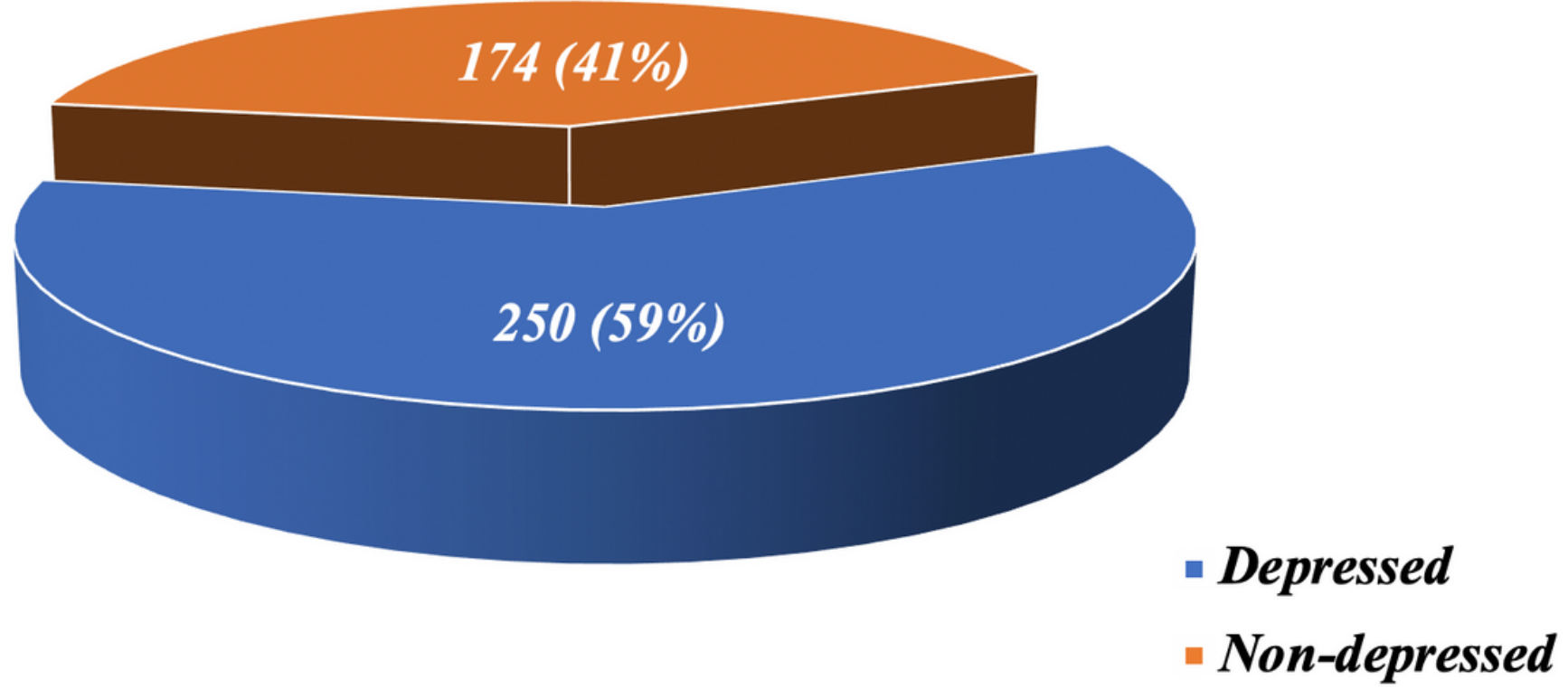

Figure 3 
The prevalence of depression among heart failure patients attending cardiac

follow-up clinic at selected government specialized teaching hospitals in Addis Ababa, Ethiopia $(n=424)$ 